\title{
Surfaces
}

\section{THE RISE OF CYBORG CULTURE OR THE BOMB WAS A CYBORG}

\section{David Porush}

Volume 4, 1994

SUR L'ÉPISTÉMOLOGIE DE LA GUERRE FROIDE

ON COLD WAR EPISTEMOLOGY

URI : https://id.erudit.org/iderudit/1064963ar

DOI : https://doi.org/10.7202/1064963ar

Aller au sommaire du numéro

Éditeur(s)

Les Presses de l’Université de Montréal

ISSN

1188-2492 (imprimé)

1200-5320 (numérique)

Découvrir la revue

Citer cet article

Porush, D. (1994). THE RISE OF CYBORG CULTURE OR THE BOMB WAS A

CYBORG. Surfaces, 4. https://doi.org/10.7202/1064963ar
Résumé de l'article

Dans le portrait qui en est fait ici, la guerre froide apparaît comme un âge non pas atomique, mais cybernétique - c'est-à-dire, un âge assoiffé d'exactitude et de certitude et structuré par la quête de la reproduction cybernétique de l'intelligence humaine. L'auteur illustre son propos en suivant l'évolution de la figure de l'androïde dans les ouvrages de science fiction de la seconde moitié du vingtième siècle. 


\title{
THE RISE OF CYBORG CULTURE OR
}

\author{
THE BOMB WAS A CYBORG
}

David Porush

\begin{abstract}
Pictured by the author as a cybernetic rather than an atomic age, the Cold War is shown to be structured by the quest for a cybernetic modelling of human intelligence capable to eliminate uncertainty. The rise of the cyborg figure in science fiction is brought into consideration as an illustration.
\end{abstract}

\section{RÉSUMÉ}

Dans le portrait qui en est fait ici, la guerre froide apparaît comme un âge non pas atomique, mais cybernétique -- c'est-à-dire, un âge assoiffé d'exactitude et de certitude et structuré par la quête de la reproduction cybernétique de l'intelligence humaine. L'auteur illustre son propos en suivant l'évolution de la figure de l'andrö̈de dans les ouvrages de science fiction de la seconde moitié du vingtième siècle.

Bruce Sterling's science fiction novels portray the cyborg future of humanity. There, centuries from now, humans have divided themselves into competitive factions based on two opposing philosophies: "Mechanism" and "Shaping." The former have designed their own ontogenetic evolution through the cultivation of various technologies, including the prosthetic, 
mechanical, and especially cybernetic ones. The Shapers rely only on biology, biochemistry, and especially molecular biology (genetics) to "shape" themselves and their own futures, primarily by extending life, sexual potency, and certain biological talents. From back here in their past, we can perceive a certain irony (out of which Sterling makes some nice satiric hay): the two human factions are really twins, seeking a shared posthuman future, though through different means. Both evolve towards artificially constructed beings who rely merely on two different arrangements of cyborg techniques to distinguish themselves from each other. The Shapers may well pride themselves on their eugencially-selected intelligence and despise the artificial computer implants and enhancements of their Mechanist doppelgangers. Yet, as one of the Mechanist spokesmen notes, "[The Shapers] might properly be defined as industrial artifacts."[1] The Mechanists may well use software implants and direct linking to computers to enhance their faculties, and abhor the messy fecundity and (what they view as "corruption") of Shaper life, but there is no denying that their mechanical prostheses change biological facts.

In one particular epoch of Sterling's future history (which he plays out over several works of fiction), this galaxial civilization is in its decadence, verging on the apocalyptic, dangerously close to achieving a critical mass or catastrophic fluctuation that will force it to "leap to a new order of complexity" (in terms Sterling borrows from chaos theory).[2] This new order will be the Post human. The speeches of many characters refer to this yearned-for future; they chide each other with gibes like, "Oh, show a little Posthuman fluidity." Sterling's hero in "The Cicada Queen" foresees the shape of the posthuman in "The Lobsters," humans who have already gone over to the far side of this utopian vision. The Lobsters have "shucked their humanity like a caul," combining some Shaper bioengineering with Mechanist tech to encase themselves in completely cyberneticized shells, after altering their biology to ensure they can survive.

The Lobsters hooked into fluidic computers or sheltered themselves from solar storms and ring-system electrofluxes.

They never ate. They never drank. Sex involved a clever cyber-stimulation through cranial plugs. Every five years or so they 'molted' and had their skins scraped clean of the stinking accumulation of mutated bacteria that scummed them over in the stagnant warmth [of their suits].

They knew no fear... They were self-contained and anarchical. Their greatest pleasure was to sit along a girder [on a space station] and open their amplified senses to the depths of space, watching stars past the limits of ultraviolet and infrared... 
There was nothing evil about them, but they were not human. As distant and icy as comets, they were creatures of the vacuum, bored with the outmoded paradigms of blood and bone. I saw within them the first stirrings of the Fifth Prigoginic Leap... as far beyond intel-/pp. 6-7/ ligence as intelligence is from amoebic life or life from inert matter. ("Cicada Queen" 77)

I find this description of one of humanity's possible futures compelling, not so much because it is attractive (which it is in some zoned-out fashion) but simply because it seems plausible. This image of the cyborg and others, also more or less plausible, have now come to dominate our postmodern landscape, expressed in literature, film, and the arts, giving rise to rich expressions too broad and numerous to catalog here.

Today, from a vantage point after the Cold War is purportedly over, it is easier to see the outline of cyborg epistemology as it grows out of seeds engineered in World War II and blossoms in Cold War culture. - From this advantageous perspective in 1993, the contest among nations and ideologies that was World War II masked an even more important war between opposing cognitive faiths, with a definite victory for cybernetic fundamentalism. In short, to understand how and why the cyborg has achieved such predominance in the 1990s, such mythological force, we must re-read World War II and the Cold War. In this paper, I hope to show how the Mechanists, the Shapers, and the Lobsters of Sterling's imagination came to be thinkable -- if not inevitable -- versions of the posthuman because of the technologies and epistemologies that won World War II.

\section{The "Atomic Age" vs. the "Cybernetic Age": The Bomb was a Cyborg}

What would happen if you asked most contemporary commentators of the period of the late 1940s and the early 1950s: What is the single most important feature of your cultural and political landscape? or, What is the largest threat to civilization? They would undoubtedly reply to both questions, "The Bomb." It is a cliché to say that what determined the politics, much of the imaginative culture, some of the nihilistic philosophy, and certainly the Byzantine dance between the superpowers USSR and USA, was the threat of detonating the apocalyptic, doomsday device known first as the Atomic Bomb and later as the Nuclear Bomb. This was so true that it is also a cliché to call the Cold War Era the Atomic Age, sometimes striking an upbeat note, ringing within it the gleaming promise of a utopian future, but more often echoing something bleak and foreboding. Certainly, the popular culture of the 1950s and 1960s reflected darker images in hundreds of novels and movies about atomic bombs, monsters created by nuclear 
fallout, like Godzilla, and parables about post-Nuclear apocalyptic worlds like "On the Beach" and "FailSafe."

I would argue, however, that the politics of the atomic bomb and nuclear weaponry is really a small subset of a much more profound and important movement, one that is now beginning to express itself in its full-blooded manifestation. Furthermore, this movement was at its core an epistemological revolution. Why does the atomic bomb fade as an icon in the 1980s and 1990s, even while nuclear weapons stockpiles increase and proliferate, to be replaced by the computer, the AI, the robot, the cyborg as the most important icon of our generation? The answer, again, is epistemological: the Atomic Bomb was a very explosive technological device, but as such was merely a symptom or manifestation of the very same epistemology that is more fundamentally represented by the cyborg, in a way I shall explain in a moment.

In order to understand the first bit of cultural genetic code that spawns this future, we need to look briefly at the human compulsion to simulate and its history.

\section{Simulations and hyperreality:}

When we are under the sway of a pretty simulation -- like those sped-up NASA animations of the Voyager probes as they slingshot around planets and zoom out of our solar system, which rely on mathematics only slightly more complicated than Kepler's -- we are seduced into inhabiting a metaphorical space where our pretenses become confused for fact, and the artificial and the natural collapse into each other. The geologically slow development of an alluvial plain is simulated by a computer program of erosion, aided by the principles of fractal geometry. Natural and achingly slow sculpture in sand and stone and water by tide and gravity and friction become pixellated images on a computer screen motivated by rational theories and digitized information. And somehow, despite the blurb on the screen reminding us that this is a NASA simulation, the images have the clarity and perfection of utter conviction.

Jean Baudrillard, rhetorical heir to Jacques Ellul -- who also critiqued technology as an apocalyptic, authonomous threat, -- locates the hyperreal in this moment of seduction and appreciation of simulations. He defines the hyperreal as when the "consumer" (reader, user) mistakes, wilfully or willy nilly, the map for the territory, the model for the thing modelled, the simulation for the original. In Baudrillard's view, this choice or 
transvaluation creates the postmodern condition of our entire culture itself. The wholesale cultural emigration to hyperreality is an historical inevitability, something quite new and dangerous as well as irresistibly fascinating. As a neo-Marxist, this rhetoric of historical inevitabilities is very strong in him. As he writes in Simulations :

[We have moved] from a capitalist-productivist society to a neo-capitalist cybernetic order that aims at total control. This is the mutation for which the biological theorization of code prepares the ground. There is nothing of an accident in this mutation. It is the end of history in which, successively, God, Man, Progress and History die to profit the code...[3]

However, I cannot take Baudrillard's apocalyptic hyperbole so seriously. Simulation is merely a special case of modelling. To simulate is to take one thing for another in a different medium. Once we accept this definition, several things become clear.

First, all art is a form of simulation and vice versa. Even when it is not mimetic, art models something. To invert the tautology, to model is also to produce art, and this never has been so clear as when we watch visual models of mathematical relations on a computer screen.

Second, thought is simulation and vice versa. The work of the brain (forget about the mind for now) is to take something from out there and translate it into another medium inside the body. Fill in the blank with your favorite version of the brain: neuro-electrochemical pudding, neurohologram, whatever. For humans, this translation occurs most forcibly as something we call thoughts, ideas or images (now we can think of the mind, if you wish).

Third, all metaphor is simulation and vice versa. To model implicates metaphor ubiquitously, as a brand of "as if" behavior.[4] The only shade of meaning introduced explicitly by the choice of the term "simulation" over the term "model" is the important sense of deception, duplicity, or dishonesty. When twins conspire to switch roles and fool their teachers it is dissimulation; but when a painting strives for trompe l'oeil and the painful naturalism of the real, then we are moved [urged, persuaded] to accept the simulacrum for the original, and we are in the grips of simulation. Since conceiving of the world as if is essentially hardwired into human cognition, since the essential mark of human intelligence is this metaphorical ability to take one thing for another, to willfully deceive ourselves, then it is hard to accept Baudrillard's claim that the hyperreal is only a postmodern condition. The hyperreal has always been with us. Indeed, it is us, or at least the essential part of ourselves that lives in our brains, a compulsion of the nervous system. 
What changed during the Cold War to deceive thinkers as astute as Baudriallard into thinking that simulation-sickness was a postmodern condition? It is that our culture then developed a whole epistemo-technology for the production of hyperreal images and codes, so that the essential urge to model and simulate and dissimulate is now exteriorized in rational systems that do the work of our nervous systems for us, better than us, and therefore seductively.

Hyperreality, then, is a condition of the mind, and that condition is the consequence or symptom of an urgency in the brain. It expresses itself simply as a more objectified or seductive aspect of "as if" behavior, where the code is abstracted from sheer imagination -- from daydreams and hallucination and phenomenological perception -- to take on a priority and inevitability and life its own. The simulations that produce hyperreality are representation of one phenomenon in another medium, an essentially and basically fictive transformation. And like fiction, the allure of simulation is that it can seduce us because it is purer, more dramatic and more attractive than the thing it purports to re-present or tell the truth about. The difference between the cultural commodity we call "fiction" and the technical-scientific commodity called "simulation" is the different contracts they sign with their consumers: a novel always has a disclaimer of reality, tacitly or explicitly; simulations, by contrast, lay claim to reality, a supposition that is a peculiarly self-reflexive, tautological, tail-biting and yet effective as dissimulation: a canard, a hoax. Fictions are more honest than simulations.

However, hyperreality does not originate in postmodernism, nor is it a historical necessity peculiar to postmodernism, nor even to the twentieth century. Rather, the origins of the hyperreal can be found in any cultural moment when humans take the metaphorical as the literal and build a new epistemology on it. I cannot here more than gesture at other signatory moments when the urge to build a virtual reality or cyberspace and its attendant utopian rhetoric and hyperbole occurs. One is the invention of the (phonemic) first and aboriginal alphabet in the South Sinai sometime circa the 15th century B.C., possibly by a Hebrew slave working the turquoise mines for Pharoah. Another is the moment Hippasos the Akousmatic invented irrational numbers in 5th century B.C. Greece and caused an uproar among the Pythagoreans, sufficient to get himself assassinated. A third is the turn from a sacramental architecture to the sacramental architexture when the Temple of Solomon is destroyed, the Jews are dispersed, and the map of the Temple is folded into the page layout of the Talmud over a fifteen century elaboration of marginalia, commentary, inerpretation and hermeneutics whose most lively heir is modern literary theory.[5] But these analogous transformations into the hyperreal all began different kinds of cold wars. 
By the 1940s, the infection of rational epistemology by chance and randomness had become problematic. Heisenbergian physics had placed probabilism at the heart of physics and method. Those who wished to find a positive formalism had to find a way to dispel the use of a random or probabilistic element, the "stochastic", from their models of nature. Historically, as we see in the development of Wiener Numbers (by Norbert, the father of cybernetics) around the time of World War I, stochastic elements were necessary in most mathematical simulations because interesting phenomena worth simulating -- like Brownian motion - -- were non-deterministic, or at least, were complex beyond any simple mechanical algebra.Yet, only random-seeming events were worth modelling because deterministic events, however complicated, were and are "trivial" in the sense mathematicians often use that word: however complicated, they pose no immediate obstacles to solution. Introducing random elements into the model was more or less a fictive strategy, a shorthand for mimicking or approximating (but not codifying) the behavior of what we now call, with post-chaos understanding "complexity." In short, where one found the stochastic in a simulation that was where you could be sure that classical mechanics failed in the face of a complex universe. Inserting a random element was tantamount to drawing terra incognita, as the place where monsters live.[6]

"Stochastic" is one of those words that reveal sublimated messages if we perform radical etymology on them. We discover that Stoxastikos in early Greek meant, quite simply, the art of guessing. It might be easy to forget amid all its successes, especially in the hard sciences, that simulation is an elaboration on the art of guessing, a stab in the dark, which is why stochastiko also gives us staccato, both the stabbing musical form and the Elizabethan word for a short dagger. Later in classical Greek, stoxastikos came to mean "prophecy," a comment, perhaps, on what the Greeks really thought about their oracle: any prophesy is merely guessing about the future, augury, the reading of signs. So it is more than linguistic coincidence that the word also came to mean, by the Medieval period, "enchantment." The idea of determining the future or reading the unreadable internal state of things is universally connected to stochastic devices: dice are thrown, lots are drawn, secret words are incanted, the wheel of fortune is spun. The I'Ching system relies upon the casting of stones to signify your spiritual condition as well as your future. The random arrangement of tea leaves at the bottom of a cup, the dealing of a well-mixed tarot deck, consulting a surely arbitrary arrangement of stars in the sky... all have hints of domesticated forms of enchantment. My daughter has a black plastic eight ball with a window at its bottom. Ask the eight ball a yes-no question and shake it; it will reply as one of eight faces of a die appears, floating in oil, to say, "Yes," "No" "Ask me later," etc. At one point, before she unmasked the oracle, she took it quite seriously.

In late eighteenth century, an entire science took its name from the systematic haphazardness implied in the word. Stoicheiometry, the science of modelling atoms of different elements, was so-called[7] because until the 
modern electron microscope, physical chemists essentially had to engage in an iterative process of "guess-timating" until they found a satisfactory model -- one that fit the facts of the behavior of a certain element. The original method involved the relative apportioning of acids and bases in a solution of the mystery element until the mixture was neutralized, a process of educated guessing. If you remember how we were taught to find the square roots of large numbers in high school (before we learned logarithms) you are familiar with this iterative process of spiralling into an answer by educated guessing.

Today, the art of stochastic modelling of future states of a system, while oracular in its motive, has almost entirely lost its mystical flavor. The way in which a computer can model certain complicated events, especially when they are displayed visually, certainly has its charm and fascination.

Simulations of certain fluid dynamics in color computer simulations, even the ones we see of a developing storm system from satellite photographs, do seem like magic, however mundane. Some of this has crept into popular mythology: WOPR, the giant computer tapped by the young hacker in the popular movie Wargames, plays oracle when it teaches itself that all strategies lead to total thermonuclear extinction. Is Wargames a myth of the Atomic Age or of the Cybernetic Age? The answer is both, in a way that I like: for as I will show next, the two are ineluctably and historically entwined: the episte-mology of cybernetics produces the atomic bomb and determines to a large extent the politics and culture of the cold war.

\section{Cyborg fundamentalism: von Neumann's rationalized Bomb}

Perhaps that oracular quality is one of the reasons why meteorology is the only science to which an entire national television station, broadcasting round the clock, has been devoted in the U.S. (The Weather Channel). It would be hard to imagine a similar stage given to, say, particle physics, although it relies on simulations, too.

The single figure most responsible for making the Weather Channel possible is an unlikely one: the late Princeton mathematician and flamboyant genius, John von Neumann. In large measure we can trace the modern American obsession with and sanguine investment in forecasting the weather to von Neumann's ill-placed confidence that his computer simulation techniques would one day predict weather not only days, but weeks and months in advance.[8] In all of this, however, the enemy was the stochastic. 
It was eliminating the stochastic -- the uncertain and probable -- in systematic modelling to which John von Neumann devoted his career. Born in 1903 in Hungary, von Neumann's life work threads through the history of the computer and what would later become known as artificial intelligence. In 1920 s he went to Göttingen from his native Hungary to escape statesponsored anti-Semitism. In 1933, he fled to Princeton from Göttingen to escape Nazi persecution of Jews again. He had an extraordinary influence on Alan Turing, and invited Turing to join him in Princeton. He eventually collaborated and competed with Norbert Wiener. He knew Claude Shannon at Bell Labs, also in New Jersey. Together, the four figures, von Neumann, Wiener, Shannon and Turing, fathered the Cybernetic Paradigm, which has since given us computers, artficial intelligence, information science, behavorism, cognitive science, game theory, and systems theory (the latter along with Ludwig von Bertalanffy.)

In 1943, von Neumann went to Los Alamos labs to work on problems central to harnessing and unleashing nuclear energy. His success made it directly possible to create the atom bombs dropped on Hiroshima and Nagasaki. Because of his history of fleeing anti-Semitism, it would be easy to read his motives for working on the atom bomb as political. In his choice of final products he might very well have been driven by strong personal desires to beat the Nazis to the punch. But in his choice of particular problems contributing to that end-product, I believe he was driven by an equally deep, equally personal, and perhaps even more persistent politics of epistemology.

Von Neumann first established himself as a mathematical prodigy for the mathematical models and explanations he offered of quantum mechanics. In this work he tried to explain away the probabilistic elements which Heisenberg's theorem introduced into our understanding of what goes on at the sub-atomic level.[9] The idea that we could only know in statistical terms where an electron might be at any given moment was totally unacceptable to von Neumann, although he never found a complete alternative. In the nineteen-thirties, von Neumann more or less single-handedly invented game theory, an attempt to describe human motives and behaviors in mathematical and logical terms.[10] He was driven to the discipline out of frustration at the success of (Kurt) Gödel's Theorem, which demolished the ideal of a consistent and complete set theory towards which von Neumann had been working with fellow mathematicians at Göttingen. Gödel's Theorem represented another telling defeat for strict determinism. Even when humans were involved, as in game theory applied to economic strategies, Neumann treated all the elements of the system as if they could be described by pure logic. For von Neumann, the human brain was the source of most of the irrationality in the world, or to put it in simulation terms, the human brain is stochastic in two senses: it is the physical incarnation -- the source -- of the uncertainty brought with the human observer's role in modern physics, and it is the source of human behavior, that most mystifying and irrational phenomenon. Von Neumann preferred to 
believe that the human was simply an automaton.[11] In fact, one of the major failures of early game theory derived from von Neumann's insistence on the strict rationalization of all elements.[12]

He was well-known in Princeton not only for his brilliant mathematics but for his elaborate cosmopolitan dinner parties, his hoard of dirty limericks, and his apparent ineptitude or brashness as a driver. "He drove on either side of the highway with equal aplomb and wrecked cars regularly"(Binary Brain 77), writes another biographer. At the risk of being accused of overreading the text of Von Neumann's life, we might explain this quirky and self-destructive habit of driving in another way if we view it in light of his habits of mind. We like to find eccentricities in our cherished scientists. The image of the unworldy, absent-minded scientists can be traced at least to Swift's Lagado academicians in Book III of Gulliver's Travels. But in the case of Von Neumann, who otherwise was so driven to control, ineptitude or eccentricity in driving is really rather inexplicable. Rather, it is clear that in all aspects of his life, even in his driving, von Neumann was devoted to overcoming the hasards of life, as the French understand it -- life's diciness. Driving demonically and quite irrationally on both sides of the road was actually an act in defense of a higher rationalism, consistent with his theoretical projects. Von Neumann was throwing down a gauntlet in the face of life's stochastic quality; he challenged the system of roads and other drivers to involve him, in the most literal possible meaning of the word, in an accident. Von Neumann loved to gamble, too. Especially at Monte Carlo. In the same vein, his mathematical cosmology seems almost certainly driven by deeper psychic and metaphysical impulses than the sheer power of logic that he prized so well. For him, the struggle between chance and determinism was an elemental duel between evil and good, and out of that war he helped forge a religion that has had powerful consequences and more converts in this century than any other dogma.

The overriding feature of von Neumann's mathematical disposition, then, was his imperialistic urge to describe nature in the terms of strict logical determinism untainted by probabilism or uncertainty.[13] As David Ritchie notes, "Von Neumann viewed life in general as a set of equations to be solved" (Binary Brain. 73). At Los Alamos, he was posed with one particularly difficult problem, which he attacked by developing a way of simulating atomic events. His solution has had fascinating fallout, so to speak. The problem was macabre: when any sufficiently large nuclear explosion occurs within a container, unless the radioactive material is properly contained and the timing of triggering explosions perfect, neutrons stream out of one side of the container, causing an asymmetrical and much weaker, although more unpredictable, blast. In order to make the most potent blast possible, a series of complex events had to be modelled so that the radioactive material would explode symmetrically. This grisly work went under the sanitized rubric of solving "the neutron diffusion problem." Von Neumann gave it the code name "Monte Carlo" for reasons we will soon see. 
Until he and Stanley Ulam, another noted mathematician, collaborated on the problem of neutron diffusion in 1943 there were generally only two sorts of modelling for complex events employed by scientists and mathematicians: deterministic (which was essentially applied mathematics and therefore is not considered simulation) and variations on stochastic techniques which is known in the scientific community simply as simulation.[14] For the purposes of this paper, however, I'll call stochastic simulation brute simulation, because it relies on the blunt introduction of a random or stochastic element for its success.

Von Neumann believed that the use of a random element in brute simulations was unacceptable, a form of contamination, cheating. It was unkosher. In fact, his aversion to stochastic modelling is at the heart of von Neumann's -- and Turing's and Wiener's -- epistemological politics alluded to above. Abhorrence of the random and statistical is clear throughout his work, not only in his modelling techniques at Los Alamos, but earlier in his work on quantum mechanics. What is more significant for this discussion is that later, in his design for the prototypical computer and in the claims he made for its capacity to emulate human intelligence, he purged any hint of random play. To get around the apparently ineluctable inclusion of the random, he devised a second kind of simulation he called "the Monte Carlo simulation," in paradoxical honor of the roulette wheel and other games of chance played in that gambling capital of Europe. In the Monte Carlo simulation, Von Neumann had devised a very good non-stochastic formula for approximating the stochastic operators in most non-trivial simulations. In other words, he had found a deterministic way to model random events. He had won yet another battle against the evil of randomness. He had also, in effect, rigged the roulette wheel in the house's favor, since when the Monte Carlo simulation works, it suggests not only that we can describe nature without relying on randomness or chance, but that nature itself is deterministic. The Monte Carlo method was so successful, it is still very much employed in simulation. Combined with some more evolved techniques, we find it applied in many disciplines, including atomic and subatomic physics, as a tool for prediction and control.[15]

After his work with simulation, or as a direct philosophical extension of it, von Neumann also proposed in great detail the prototypical architecture of the modern computer still in use today. The short, potent monograph in which he lays out the territory is The Computer and The Brain.[16] Though published posthumously in 1957 -- von Neumann died of cancer almocertainly caused by his insistence on witnessing the test explosions of atomic bombs, fruits of his own labor -- and based on the Silliman lectures he delivered at Yale in 1956, it explicates the work he and many others had done in computer design for the decade previous, at the beginning of the Cold War. After working on the Atom Bomb, von Neumann made smooth transition to apply what he had learned about eliminating chance to a description of the human mind. In fact, von Neumann was taking up a project he was working on before the advent of the war. He was obsessed by 
the way the Heisenberg equations introduced an intolerable element of randomness into science's portrait of the universe at its most quick: in the orbit of an electron around a nucleus. One of the expressions of this project was his game theory, an attempt to create a rational model for human motives and actions in carefully circumscribed arenas. If, he reasoned, you could pin down and express fully -- simulate -- all human actions in rational formal terms, then you had some hope of eliminating the random from our picture of the quantum world.

So in that simple copula of the title -- The Computer AND the Brain - -- lay an entire program for scientific study we now know as Artificial Intelligence. The title proposes a two-way metaphor, a mythological symmetry or equation: The computer is a brain and the brain is a computer, each a simulation of the other.

Indeed the book is only half devoted to a design for computers. The second half lays out a mechanical portrait of the nature of individual neurons and how they transmit information, entirely premised on the supposition that neurons are binary, conveniently like the logical switches or gates von Neumann proposed as the basis for some of the first giant computers such as ENIAC and EDVAC (at University of Pennsylvania 1948), and his own MANIAC and JONIAC at the Institute for Advanced Study in Princeton in 1950. This neural metaphor is so powerful that even today, in elementary physiology classes, the nerve is still portrayed as a simple on-off mechanism, even though neuroscientists now know that neurons, especially those controlling complex events (like neurons in the cortex of the brain and Purkinje neurons that regulate the heart), are much more elusively indeterminate. [17] So von Neumann was moving from a metaphor founded on /pp. 21-22/ pure faith-- the nerve is a binary switch -- to embrace a model that has since had enormous influence.

In sum, in all these related pursuits -- explaining away Heisenberg's uncertainty principle, game theory, and his later work simulating the atom bomb's explosion computer modelling of the brain -- we can trace von Neumann's dedication to eliminating undecidability in favor of the control promised by deterministic schemes of logic.

\section{Norbert Wiener's leap of faith}

This brings us to cybernetics, or rather, returns us to the question of simulating the human mind, which involves the related nexus of fields: computer science, cybernetics, artificial intelligence, behaviorism, cognitive 
psychology, information theory, and simulation. Cybernetics was born almost at the same time as the Monte Carlo simulation. Here again, the War and the roots of the Cold War are elided as expressions of the same epistemological movement.

In 1943, von Neumann and Norbert Wiener, along with Gregory Bateson, Jerome Lettvin, Margaret Mead, Walter Pitts (who was working with neurophysiologist Warren McCullough on a mechanical model of the nerve involving switching mechanisms) and others met over several months in Boston to give rise to a new interdisciplinary study of the role of information in systems.[18] In these Macy meetings (they were sponsored by a wealthy scion, Josiah Macy, Jr.) Wiener dubbed the new science cybernetics, another word whose Greek root carries with it the secret intention of the science. Kybernotos, in the original Greek, meant "pilot" or "steersman," and cybernetics was the science devoted to describing the pilot in all systems of information, the controlling intelligence for animals and machines, including the mind that steers human behavior and communication.

In his description of the original conception of cybernetics, Wiener makes it clear that he is von Neumann's fellow sectarian as well as his collaborator. [19] He, too, was horrified by hasard.

Yet, in recognition of a fundamental element of chance in the texture of the universe itself," Wiener writes, "these men [Freud, Gibbs, and Heisenberg] are close to one another and close to the tradition of St. Augustine. For this random element, this organic incompleteness, is one without too violent a figure of speech we may consider evil; the negative evil which St. Augustine characterizes as incompleteness. (Human Use 11)

In Wiener's explanation, cybernetics is also conceived, as in Von Neumann's scheme, as an answer to the unholy introduction of uncertainty into science by quantum physics.

Later in The Human Use of Human Beings, Wiener makes even more explicit his metaphysical conception of cybernetics:

The machine, like the living organism, is, as I have said, a device which locally and temporarily seems to resist the the general tendency for the increase of entropy. By its ability to make decisions, it can produce around it a local zone of organization in a world whose general tendency is to run down. 
The scientist is always working to discover the order and organization, and is thus playing a game against the arch-enemy, disorganization. Is this devil Manichean or Augustianian? Is it a contrary force opposed to order or is it the very absence of order itself?... The Mani- chean devil is playing a game of poker against us and will resort readily to bluffing; which as von Neumann explains in his Theory of Games, is intended not merely to enable us to win on a bluff, but to prevent the other side from winning on the basis of a certainty that we will not bluff. Compared to this Manichean being of refined malice, the Augustinian devil is stupid. He plays a difficult game, but he may be defeated by our intelligence as thoroughly as by a sprinkle of holy water...

[As Einstein said]...'The Lord is subtle but isn't simply mean.'(35)

Von Neumann, St. Augustine, Einstein. Wiener intones the saints of determinism and rationality. He also exorcises the Augustinian devil by taking Maxwell's formula for entropy in a closed heat system and applying it to information. Wiener even adopted the same term; the randomness or assortment of possible states was the devilish entropy in a system; the good information extracted from that noise was negentropy, a measure of the amount of sense made by a communications system. Thus, Maxwell's demon, more a Manichean shifty sort, was reduced in Wiener's mind to a manageable Augustinian demon by defining the amount of entropy (disorder) he created as equivalent to the negentropy (information) he needed to do his evil work of directing hot atoms into one chamber and cold atoms into another. This is the very rock-bottom piece of fiction on which the idea of quantifying information is established, in pursuit of the hope that the actions of a human observer can also be quantified.

Everything thereafter in cybernetics follows logically. The notion of the binary unit or bit (what Bateson called the "difference which makes a difference" in his Ecology of the Mind) Shannon first suggested in 1940, but it was enormously refined and given a larger context under the influence of Wiener's definition and his use of the Bolzmann constant. The crucial notions of positive and negative feedback - -- especially as applied to organic and mechanical systems equally - -- came out of the Boston meetings in 1943 and now could be rationalized by the application of a formula for information. (It would soon extend explicitly to human behaviors in the form of B.F. Skinner's behaviorism, another première Cold War "science.") The idea of a controlling servomechanism or central processing unit, the design for a mechanical brain, and the assumption that the nerve holds not only information but the same kind of information as a communications machine like the telephone -- all these make logical sense only if you took Wiener's leap of faith. 
Again, The Bomb -- especially as it was to be understood in the Cold War -becomes the instrument of this epistemological movement. Wiener's work in World War II eventually helped haunt the nightmares of the 1950s and 60s. One of the most horrifying features of the Atomic Apocalypse was the idea that a warhead could be delivered from remote, safe bunkers across the oceans. (The absurd nightmare quality of this notion is nowhere better captured than in "Dr. Strangelove," the 1965 movie.) The sanitized version of war this permits, the ultimate dehumanization of human destruction, was made possible by advances in guidance systems that evolve from Wiener's work. Wiener's first application of Wiener numbers and cybernetics was to developing a feedback system used in the tracking system for anti-aircraft gunnery and by extension the guidance systems for rockets and missiles. These guidance servomechanisms were essentially the first primitive cybernetic computers -- thinking machines responsive to their environment, what Pynchon calls in Gravity's Rainbow the schwarzgerat -- the dark things or black boxes -- that became standard in all missiles of the Cold War. Gravity's Rainbow, of course, is, among other things, a long meditation on how the Atomic Missile, which so haunts Cold War consciousness, was the consequence of cybernetic epistemology.

\section{Ciphering the soul: Alan Turing}

The cybernetic metaphor that the brain is a [formalizable] machine did not originate with Wiener, or even John von Neumann. A few years earlier, as early as 1936, Alan Turing was exploring the mathematical imitation of computers. But by "computers" Turing at this point merely meant the only known sense of the word: humans doing mathematical calculations. Yet even in this early work Turing entertains the idea of a machine capable of imitating those human processes.

Earlier that year, Turing was to attend a lecture course by von Neumann, who was visiting Cambridge University from Princeton. Although the course was not about computation by machine it did concern the pure mathematical underpinning of quantum theory, in which von Neumann was still engaged as part of his battle to find a deterministic solution for Heisenberg's Uncertainty Principle.[20]

Claude Shannon later codified the Turing proposition by making a random element the foundation of a learning machine. His watershed paper was "Computability by Probabilistic Machines," [21] in which he poses the 
question, "Is there anything done by a machine with a random element but not by a deterministic machine?" which he also answered in the affirmative.

The play "The Enigma" about Alan Turing's life dramatically captures the complex of libido and metaphysics which underpinned Turing's faith -- there is no word more appropriate -- that the soul, the psyche, could be embodied in a machine, a delusion which this play traces to Turing's early homosexual fixation on a schoolmate who dies tragically. Turing conceives a fantasy whereby his friend, the essence of his friend, could be resurrected and programmed into a mechanical device. I don't have space to explore the implications of this psychoanalytical insight into Turing; but even if it is only suppositious at best, it captures the eerie mood of the cybernetic oxymoron, the image of a ghost in the machine, of imprisoning the soul in mathematics and formal logic.

Again, in Turing's case, World War II is crucial in writing the genetic code of the Cyborg Cold War future. Turing's work would probably have been obscured were he not involved in the British effort to crack the brilliant Nazi code scheme. Turing achieved fame -- and later notoriety -- because he successfully applied his logical principles to deciphering the ultimate Cypher.

\section{Cyborg lit}

The rise of cybernetics in this broad and interconnected community of scientists is not as sudden and spontaneous as it may appear. Rather it was the manifestation of a deep current in Western philosophy and culture. Literary culture, for instance, had persistently re-invented the image of the mechanized or artificial human which can be traced back to the Greek myths of Talos and Galataea in the Hellenistic period. The 18th century was fascinated with automata to the point that Descartes, Liebniz and Pascal all considered the question of a mechanical human, and Swift wrote a satiric attack on sermons that manipulated the human spirit as if it were mechanical. Charles Babbage's attempt to create a mechanical calculator in 1829 might have changed the course of technological history had he succeeded (see The Difference Engine by William Gibson and Bruce Sterling). In the first half of the 20th century we find a close relation between philosophy, literature and cyborg imaginings in science. Turing, for instance, was influenced by a viewing of G.B. Shaw's Pygmalion and Back to Methusela, both of which treat the theme of artificial humans. And this persistent undercurrent is symbolic of a deeper concern with whether the universe, including humans, is a machine or whether it is spirit. Cybernetics gets its name and particular force from the relatively new concept that the operations of the brain -- thoughts themselves -- are mechanical, and could 
be simulated in actual hardware.[22] Yet even these persistent speculations might have remained in some shadowed realm between mathematics and science fiction were it not for World War II.

But the advent of World War II gave this epistemological undercurrent a necessary translation into lethal hardware, and therefore an immediate political force. It brought to the forefront these three figures - Wiener, von Neumann, Turing -- who might otherwise have been interesting devotees of the church of determinism, brilliant mathematicians but irrelevent as philosophers or inventors of a new culture. The war essentially fashioned a momentous cultural force out of their abstruse and academic concerns over the efficacy of logic and rationality. As a result, the cyborg ideal does not simply fade into inconsequentiality with the defeat of Nazism. The presence of cybernetics' firstborn, the Atomic Bomb, makes it impossible to ignore. The mushroom cloud is simply the very large trace -- the cultural icon-undererasure -- obscuring a much more intangible yet more monumental explosion in epistemology called cybernetics. It is the accomplice term which first masks and then becomes simply the shock troops for a larger epistemological invasion. Early cybernetic writers like Kurt Vonnegut, Jr. (Player Piano, 1952) and William Burroughs (The Soft Machine, 195x) are quick to recognize the association.

As we survey the Cold War landscape, even as it recedes from us in the last five years especially, everywhere we look we see a burgeoning of the computer and enactment of a powerful drama between human and cybernetic technology, a struggle between allegience to humanism and naturalism, on the one hand, and an encouragement to systems of control and information on the other. Music, film, literature, and dance express the labor pains of humans as they give birth to themselves as a new order of being, what Burroughs called "a soft machine," partly natural, partly artificial... the cyborg. Some parts of the culture celebrate this transformation, some mourn it, and even others inspect it rationally as an inevitable evolutionary step. I have even argued elsewhere that the arts are not just expressions of the struggle, but they, particularly literature, become the site of an epistemological battle. What's at stake is the territory of the human, besieged by cybernetic encroachment. The major artillery in this war involved turning the weapons of artificial intelligence and computers and formal systems of control and communication to the advantage of art, to resist the machine with the guerrilla weapons of literature: metaphor, irrationalism, transcendence, ambiguity, and silence. Yet, even in this guerrilla resistance movement, much of this anti-cybernetic postmodern art couldn't help but express our cyborg nature, the wedding between the ultraexpressive artist and the rational technologist rolled into one. One cannot understand postmodernism without appreciating the overwhelming view of humans as soft machines: part free, part robot; part phenomenological ontology, part rational epistemological system. 
So if we judge an era by what persists after it, what endures, what is abstracted from it, there is no doubt that the Cold War Era was a Cybernetic, not an Atomic Age, and its legacy is the ubiquitous image of the cyborg. The number of important postmodern literary texts that are directly and explicitly concerned with this momentous explosion forms a robust subgenre which I have elsewhere called "cybernetic fiction" or CF for short.[23] John Barth's Giles Goat-Boy (1963), William Burroughs' The Soft Machine and Nova Express, Samuel Beckett's The Lost Ones (1973), Italo Calvino's TZero (1967)[24] and Invisible Cities (1971), Don DeLillo's White Noise (1986), Joseph McElroy's PLUS (1977), and Thomas Pynchon's $V$. (1963), The Crying of Lot 49 (1967) and Gravity's Rainbow (1973), Marianne Hauser's The Talking Room (1975), and many works by Stanislaw Lem, but notably Cyberiad, Mortal Engines (1972), and Fiasco (1985), The Difference Engine, Foucault's Pendulum by Umberto Eco, Haruki Murakami's Hardboiled Wonderland or The End of the World (1991) are just a few titles in this genre All these texts share a strategy in which the author adopts the guise of a cybernetic device or a highly cyberneticised language, in effect, suggesting that their texts are cybernetic systems of human communication. Each of these authors explores the power and seductiveness that the root metaphor in cybernetics holds for a practitioner of literature: that literary expressiveness is best viewed as a mechanical process of selection among alternatives. Calvino's essay "Cybernetics and Ghosts" addresses this explicitly. In it, Calvino goes so far as to suggest that the author's mind is nothing more than an elaborate cybernetic mechanism devoted to sorting through the language looking for new and surprising combinations (thereby creating new information, according to cybernetic theory, out of a kind of mental noise).

Rather than being a conduit for genius or insight, the author is merely a hyper-evolved device for sorting through the language and seeking the most striking combinations that express some deeper, unreachable realm. Stripped of his delusions of romantic "inspiration" and other obsolete and grandiose explanations of creativity, the author is now revealed as a cybernetic device, a machine that takes dictation from la langue (to put it in structuralist terms) and creates individualistic utterances, les paroles. Calvino poses the question, "Will we have a machine capable of replacing the poet and author? Just as we already have machines that can read, machines that can make translations and summaries, will we also have machines capable of conceiving and composing poems and novels?"

However we take this question, as whimsy, irony, satire, or at face value, Calvino at least delineates the unifying feature at the heart of all cybernetic fictions: All of them explicitly or implicitly suggest that the human mind is a controlling mechanism whose language output forms a blueprint of its own operations; that language is a system of signs in which the author behaves according to a mechanical selection procedure or system or code; and that therefore the fictional text is a self-referential simulation game of the deep and elusive mental processes of creation. 
At the same time, paradoxically, the effect of this cybernetic guise by cybernetic fictions is ironic: it defeats, undermines, or displays the insufficiency of such cybernetic modelling, especially through the use of common postmodern games: paradox, silence, de-contextualization, selfreflexive structures, and complex, ambiguous "strong" metaphors that generate competing interpretations. In essence, cybernetic fiction is partly devoted to refuting the assumption -- underpinning many aspects of artificial intelligence research (AI), recent schools of cognitive psychology, neurophysiology and brain science, behaviorism, and systems theory -- that human expression can be simulated in a system of relationships governed by formal cybernetic laws.

This relationship between cybernetic fiction (henceforth cf) and cybernetics, however apparently ambiguous, then actually can be characterized as $a$ war of epistemologies over who does the better job of describing intelligence. In this context, what does the genre cf suggest about the relationship between simulation and literature? Specifically, if this dialectic does illustrate a deeper conflict at the epistemological level between what becomes mechanical knowing and what becomes postmodern knowing, then what is it that postmodern literary texts simulate? What alternative model of intelligence does $\mathrm{cf}$ in particular offer?

In my view, cf takes for granted the general veracity and power of literary discourse to describe and model reality, and in particular to model ontological cognition, to simulate intelligence expressing its intelligence. In other words, $c f$ simulates its own means of production. Understanding this explains the meaning of the massive self-reflection and cognitive concern with language itself that dominates postmodern fictions, whether cf or otherwise. At the same time, cf rescues itself from the determinism at the heart of cybernetics by playing the simulation game "for keeps". It insists that its own use of language is the best model it has of its own intelligence, and then it uses that language with a vengeance, unleashing all the tools that make cybernetic descriptions of language (or AI attempts at simulating natural language) seem silly, trivial, and woefully insufficient by comparison: complex self-reference, metaphor, silence, ambiguity and non-exclusive polysignation.

In sum, the Cold War enacts another silent struggle between science and literature over which medium for modelling the human mind does the better job of it: hardware-software systems or imagination expressed in a selfdefamiliarizing language. Literatures like $\mathrm{cf}$ and the new breed of cyberpunk and post-cybernetic sf genres continue to express the mythological tension. Meanwhile, new literary forms like hypertext have begun to infiltrate the computer and exploit its power in ways that couldn't be accomplished on paper, the first of the truly computerized literatures, and harbingers of 
multi-sensory art that will come in cyberspace. Hundreds of articles and books are being written about a cyborg technology that hasn't even been invented yet, virtual reality or cyberspace, urging us on even further into a cybernetic embrace. If we accept that The Bomb is simply another cyborg expression of a deeper and more fundamental, even fundamentalist, movement in science that blossomed in WWII, many more facts of our postCold War landscape are explained, and a certain continuity in history -- even an inevitability - -- towards the evolution of Mechanists, Shapers, and Lobsters becomes both thinkable and comprehensible.

\title{
David Porush \\ Rensselaer Polytechnic Institute
}

\author{
Surface Page d'Acceuil/Home Page
}

[1]Bruce Sterling, "Cicada Queen," Crystal Express (New York: Arkham House, 1989; Ace 1990): 49.

[2]Sterling's use of Prigogine's (he would say "Prigoginic") theory is widespread throughout his oeuvre, which includes The Artificial Kid (Ace, 1987); Schismatrix (Arbor House, 1985; Ace, 1986); Islands in the Net (1989) and his collaboration with William Gibson, The Difference Engine (1991). Indeed, even the titles -- Crystal Express, Islands in the Net, Schismatrix -- allude to images of moving, growing lattices of organization that survive in a universal tide towards entropy and that leap across schisms to new orders of complex integration. Space will not permit me here to untangle all the many images and speculations about the future influence of Prigogine's theories that Sterling offers us throughout his fiction. For a closer analysis of the relationhip between Sterling's work and Prigogine's see Porush, "Prigogine, Chaos, and Contemporary SF," Science Fiction Studies 18;3 (1991): 367-387.

[3]Jean Baudrillard, Simulations. trans. Paul Foss, Paul Patton, and Philip Beitchman (New York: Semiotext(e), 1983): 111.

[4]Hans Vaihinger, The Philoosphy of "AS IF": A System of the Theoretical, Practical and Religious Fictions of Mankind, trans. C.K. Ogden (1924;

London: Routeledge \& Kegan Paul, 1965).

[5]See D. Porush, "Transcendence at the Interface," Thinking Robots, An Aware Internet, and Cyberpunk Librarians, ed R. Bruce Miller and Milton T. Wolf (Chicago: LITA Proceedings, 1992).

[6]Later, in the 1970s and 80s, through the science of chaos (properly called deterministic chaos) and the work of Ilya Prigogine, simulators discovered that many of those most complex systems that formerly required a statistical or random element to even approximate, are actually nonlinear far-from- 
equilibrium systems that can be modelled by using nonlinear differential equations. In other words, chaotic systems are deterministic, not stochastic. The reason everyone makes all the fuss is because chaos is a victory for determinism. But that's another chapter.

[7]According to the Oxford English Dictionary, was coined by J.B. Richter in 1792.

[8]See James Gleick's discussion of Neumann's role in influencing the U.S. investment in weather forecasting in Chaos: The making of a new science, pp. $17-20$. When we speak about the deterministic simulation and prediction of weather, I'm always reminded of Raymond Roussel's paverpunner in his curious collection of mechanical oddities, Locus Solus. In one scene, Canterel, the genius scientist-artist-inventor who presides over Locus Solus designs a floating machine that, driven by the winds, assembles an elaborate mosaic. The success of the mosaic in turn relied on Canterel's accurate prediction of minute fluctuations in local winds days in advance so that he could literally program this machine. See my discussion of the modernist discourse and Roussel's absurd machines in The Soft Machine.

[9]Von Neumann, Mathematical Foundations of Quantum Mechanics (Princeton: Princeton Unviersity Press, 1955).

[10]John Von Neumann, Theory of Games and Economic Behavior (1944; Princeton: Princeton University Press, 1953).

[11]John von Neumann, The Computer and the Brain (New Haven: Yale UP, 1954). This essay is built entirely on the fundamental premise that the human nervous system is what he calls "an efficiently organized large natural automaton"(50-51) subject to deterministic mathematical modelling.

[12]David Ritchie, The Binary Brain: Artifcial Intelligence in the Age of Electronics. (Little, Brown, 1984), p. 76

[13]It is important to note that randomness is distinct from calculations of statistical (therefore probabilistic) distribution or statistical mechanics. As Wiener himself writes, "The functional part of physics... cannot escape considereing uncertainty and the contingency of events. It was the merit of Gibbs to show for the first time a clean-cut scientific method for taking this contingency into consideration."(The Human Use of Human Beings 8).

[14]Francis Neelamkavil, Computer Simulation and Modelling (Wiley \& Sons, 1987): 287.

[15]See, for example, Michael Creutz, "Microcanonical Monte Carlo," in Simulation at the Frontiers of Science, ed. John Young, V. Wayne Higgins and Robert Hawkins (San Diego: Society for Computer Simulation, 1986): 57-60.

[16](New Haven: Yale University Press, 1958).

[17]For a broad discussion of new views of the neurons, see D. Porush, "Cybernetic Fiction, Nerves and Metaphors," SCIT (Kingston, Ontario: Queens University, 1988). 
[18]Steve J.Heims, The Cybernetics Group (Cambridge, Mass.: MIT Press, 1991).

[19]See Steve J. Heims, John von Neumann and Norbert Wiener: From mathematics to the technologies of life and death (Cambridge, MA: MIT Press, 1980).

[20]Turing's biographer speculates that von Neumann's lectures were so influential that they moved Turing to apply to a fellowship at Princeton, which he took the next year (1936). Andrew Hodges, Alan Turing: The Enigma, (Simon and Schuster, 1983)

[21]Originally published in Automata Studies.

[22]Actually, La Métrie explicitly proposes the idea, in the 18th century, in his L'Homme, la machine, essentially attacking Descartes for exempting humans from the Cartesian worldview of a clockwork universe. But of course, the actual physiological properties of the brain were beyond his century's science.

[23]See The Soft Machine.

[24]I consider Calvino's work and its relation to cybernetics in "Cybernetic Fiction and Postmodern Science," New Literary History 20;2 (Winter, 1989): 373-96. 